\title{
Legal Preparedness:
}

Care of the Critically III and Injured During Pandemics and Disasters: CHEST Consensus Statement

Ms. Brooke Courtney, JD, MPH, Mr. James G. Hodge Jr, JD, LLM, Dr. Eric S. Toner, MD, Ms. Beth E. Roxland, JD, MBioethics, Mr. Matthew S. Penn, JD, MLIS, Dr. Asha V. Devereaux, MD, MPH, FCCP, Dr. Jeffrey R. Dichter, MD, Dr. Niranjan Kissoon, MBBS, FRCPC, Dr. Michael D. Christian, MD, FRCPC, FCCP, and Dr. Tia Powell, MD on behalf of the Task Force for Mass Critical Care

Office of Counterterrorism and Emerging Threats (Ms Courtney), Office of the Commissioner, US Food and Drug Adminstration, Silver Spring, MD; Arizona State University Sandra Day O'Connor College of Law (Mr Hodge), Tempe, AZ; UPMC Center for Health Security (Dr Toner), University of Pittsburgh Medical Center, Baltimore, MD the NYU School of Law (Ms Roxland), NYU Langone Medical Center, New York, NY; Public Health Law Program (Mr Penn), Office for State, Tribal, Local, and Territorial Support, US Centers for Disease Control and Prevention, Atlanta, GA; Sharp Hospital (Dr Devereaux), Coronado, CA; Allina Health (Dr Dichter), Minneapolis, MN; Aurora Healthcare (Dr Dichter), Milwaukee, WI; BC Children's Hospital and the Sunny Hill Health Centre (Dr Kissoon), University of British Columbia, Vancouver, BC, Canada; the Royal Canadian Medical Service (Dr Christian), Canadian Armed Forces and Mount Sinai Hospital, Toronto, ON, Canada; and Montefiore Medical Center (Dr Powell), Albert Einstein College of Medicine, New York, NY

\section{Abstract}

BACKGROUND—Significant legal challenges arise when health-care resources become scarce and population-based approaches to care are implemented during severe disasters and pandemics. Recent emergencies highlight the serious legal, economic, and health impacts that can be associated with responding in austere conditions and the critical importance of comprehensive, collaborative health response system planning. This article discusses legal suggestions developed by the American College of Chest Physicians (CHEST) Task Force for Mass Critical Care to support planning and response efforts for mass casualty incidents involving critically ill or injured patients. The suggestions in this chapter are important for all of those involved in a pandemic or disaster with multiple critically ill or injured patients, including front-line clinicians, hospital administrators, and public health or government officials.

METHODS-Following the CHEST Guidelines Oversight Committee's methodology, the Legal Panel developed 35 key questions for which specific literature searches were then conducted. The literature in this field is not suitable to provide support for evidence-based recommendations. Therefore, the panel developed expert opinion-based suggestions using a modified Delphi process resulting in seven final suggestions.

RESULTS-Acceptance is widespread for the health-care community's duty to appropriately plan for and respond to severe disasters and pandemics. Hospitals, public health entities, and 
clinicians have an obligation to develop comprehensive, vetted plans for mass casualty incidents

CORRESPONDENCE TO: Michael D. Christian, MD, FRCPC, FCCP, Royal Canadian Air Force, Mount Sinai Hospital and University Health Network, Department of Medicine and Dalla Lana School of Public Health, University of Toronto, 600 University Ave, Rm 18-232-1, Toronto, ON, M4X 1P4, Canada; michael.christian@utoronto.ca.

Ms Roxland is currently at the Office of the Chief Medical Officer, Johnson \& Johnson (New Brunswick, NJ).

Collaborators: Executive Committee: Michael D. Christian, MD, FRCPC, FCCP; Asha V. Devereaux, MD, MPH, FCCP, co-chair; Jeffrey R. Dichter, MD, co-chair; Niranjan Kissoon, MBBS, FRCPC; Lewis Rubinson, MD, PhD; Panelists: Dennis Amundson, DO, FCCP; Michael R. Anderson, MD; Robert Balk, MD, FCCP; Wanda D. Barfield, MD, MPH; Martha Bartz, MSN, RN, CCRN; Josh Benditt, MD; William Beninati, MD; Kenneth A. Berkowitz, MD, FCCP; Lee Daugherty Biddison, MD, MPH; Dana Braner, MD; Richard D Branson, MSc, RRT; Frederick M. Burkle Jr, MD, MPH, DTM; Bruce A. Cairns, MD; Brendan G. Carr, MD; Brooke Courtney, JD, MPH; Lisa D. DeDecker, RN, MS; COL Marla J. De Jong, PhD, RN [USAF]; Guillermo Dominguez-Cherit, MD; David Dries, MD; Sharon Einav, MD; Brian L. Erstad, PharmD; Mill Etienne, MD; Daniel B. Fagbuyi, MD; Ray Fang, MD; Henry Feldman, MD; Hernando Garzon, MD; James Geiling, MD, MPH, FCCP; Charles D. Gomersall, MBBS; Colin K. Grissom, MD, FCCP; Dan Hanfling, MD; John L. Hick, MD; James G. Hodge Jr, JD, LLM; Nathaniel Hupert, MD; David Ingbar, MD, FCCP; Robert K. Kanter, MD; Mary A. King, MD, MPH, FCCP; Robert N. Kuhnley, RRT; James Lawler, MD; Sharon Leung, MD; Deborah A. Levy, PhD, MPH; Matthew L. Lim, MD; Alicia Livinski, MA, MPH; Valerie Luyckx, MD; David Marcozzi, MD; Justine Medina, RN, MS; David A. Miramontes, MD; Ryan Mutter, PhD; Alexander S. Niven, MD, FCCP; Matthew S. Penn, JD, MLIS; Paul E. Pepe MD, MPH; Tia Powell, MD; David Prezant, MD, FCCP; Mary Jane Reed, MD, FCCP; Preston Rich, MD; Dario Rodriquez, Jr, MSc, RRT; Beth E. Roxland, JD, MBioethics; Babak Sarani, MD; Umair A. Shah, MD, MPH; Peter Skippen, MBBS; Charles L. Sprung, MD; Italo Subbarao, DO, MBA; Daniel Talmor, MD; Eric S. Toner, MD; Pritish K. Tosh, MD; Jeffrey S. Upperman, MD; Timothy M. Uyeki, MD, MPH, MPP; Leonard J. Weireter Jr, MD; T. Eoin West, MD, MPH, FCCP; John Wilgis, RRT, MBA; ACCP Staff: Joe Ornelas, MS; Deborah McBride; David Reid; Content Experts: Amado Baez, MD; Marie Baldisseri, MD; James S. Blumenstock, MA; Art Cooper, MD; Tim Ellender, MD; Clare Helminiak, MD, MPH; Edgar Jimenez, MD; Steve Krug, MD; Joe Lamana, MD; Henry Masur, MD; L. Rudo Mathivha, MBChB; Michael T. Osterholm, PhD, MPH; H. Neal Reynolds, MD; Christian Sandrock, MD, FCCP; Armand Sprecher, MD, MPH; Andrew Tillyard, MD; Douglas White, MD; Robert Wise, MD; Kevin Yeskey, MD.

$\mathrm{COI}$ grids reflecting the conflicts of interest that were current as of the date of the conference and voting are posted in the online supplementary materials.

DISCLAIMER: American College of Chest Physicians guidelines and consensus statements are intended for general information only, are not medical advice, and do not replace professional care and physician advice, which always should be sought for any medical condition. The complete disclaimer for this consensus statement can be accessed at http://dx.doi.org/10.1378/chest.1464S1.

Author contributions: B. C. had full access to all of the data in the study and takes responsibility for the integrity of the data and the accuracy of the data analysis. B. C., J. G. H., E. S. T., B. E. R., M. S. P., A. V. D., J. R. D., N. K., M. D. C., and T. P. contributed to the development of PICO questions; B. C., J. G. H., E. S. T., B. E. R., M. S. P., A. V. D., and T. P. conducted the literature review; B. C., J. G. H., E. S. T., B. E. R., M. S. P., A. V. D., J. R. D., N. K., M. D. C., and T. P. contributed to development of expert opinion suggestion; B. C., J. G. H., E. S. T., B. E. R., M. S. P., A. V. D., J. R. D., N. K., M. D. C., and T. P. contributed to the conception and design, or acquisition of data, or analysis and interpretation of data from the Delphi process; B. C., J. G. H., E. S. T., B. E. R., M. S. P., A. V. D., and T. P. developed and drafted the manuscript; and J. R. D., N. K. and M. D. C. revised the manuscript critically for important intellectual content.

Financial/nonfinancial disclosures: The authors have reported to CHEST the following conflicts: Ms Courtney serves as a speaker for the US Food and Drug Administration on legal preparedness issues. She has participated in the Institute of Medicine's crisis standards of care efforts. Her husband is an attorney in a law firm that represents clients in the pharmaceutical industry. Mr Hodge has received federal and private sector grants on legal preparedness. He holds stock in an international pharmaceutical company but it does not conflict with this manuscript. Ms Roxland had no conflicts at the time the manuscripts were being drafted through the date of actual submission to CHEST, but is now employed as Bioethics \& Strategy Leader in the Office of the Chief Medical Officer at Johnson \& Johnson. The remaining authors report no potential conflicts of interest exist with any companies/organizations whose products or services may be discussed in this article.

Endorsements: This consensus statement is endorsed by the American Association of Critical-Care Nurses, American Association for Respiratory Care, American College of Surgeons Committee on Trauma, International Society of Nephrology, Society for Academic Emergency Medicine, Society of Critical Care Medicine, Society of Hospital Medicine, World Federation of Pediatric Intensive and Critical Care Societies, World Federation of Societies of Intensive and Critical Care Medicine.

Other contributions: We thank Alicia Livinski, MA, MPH, US Department of Health and Human Services, for her extensive literature review work; Kim Weidenaar, JD, with the ASU Sandra Day O'Connor College of Law for her significant contribution to the legal literature review; and John Parker, MD, Major General (Retired), for his important insights and contributions to this effort. We also thank Jamal Bracken, MS, Johns Hopkins University School of Medicine, for his considerable assistance with the literature and Gregory Sunshine, JD, US Centers for Disease Control and Prevention, for his helpful research on the international issues. The opinions expressed within this manuscript are solely those of the author (B. C.) and do not represent the official position or policy of the US Food and Drug Administration. The views expressed in this article are those of the author (M. S. P.) and do not necessarily reflect official policy of the Centers for Disease Control and Prevention or the US Government. The opinions expressed within this manuscript are solely those of the author (M. D. C.) and do not represent the official position or policy of the Royal Canadian Medical Service, Canadian Armed Forces, or the Department of National Defence.

Role of sponsors: The American College of Chest Physicians was solely responsible for the development of these guidelines. The remaining supporters played no role in the development process. External supporting organizations cannot recommend panelists or topics, nor are they allowed prepublication access to the manuscripts and recommendations. Further details on the Conflict of Interest Policy are available online at http://chestnet.org. 
involving critically ill or injured patients. Such plans should address processes for evacuation and limited appeals and reviews of care decisions. To legitimize responses, deter independent actions, and trigger liability protections, mass critical care (MCC) plans should be formally activated when facilities and practitioners shift to providing MCC. Adherence to official MCC plans should contribute to protecting hospitals and practitioners who act in good faith from liability. Finally, to address anticipated staffing shortages during severe and prolonged disasters and pandemics, governments should develop approaches to formally expand the availability of qualified healthcare workers, such as through using official foreign medical teams.

CONCLUSIONS-As a fundamental element of health-care and public health emergency planning and preparedness, the law underlies critical aspects of disaster and pandemic responses. Effective responses require comprehensive advance planning efforts that include assessments of complex legal issues and authorities. Recent disasters have shown that although law is a critical response tool, it can also be used to hold health-care stakeholders who fail to appropriately plan for or respond to disasters and pandemics accountable for resulting patient or staff harm. Claims of liability from harms allegedly suffered during disasters and pandemics cannot be avoided altogether. However, appropriate planning and legal protections can help facilitate sound, consistent decision-making and support response participation among health-care entities and practitioners.

\section{Introduction}

During catastrophic health emergencies, significant legal challenges and concerns arise as health-care resources become scarce and the provision of care shifts along the continuum of care from individual to population-based approaches. ${ }^{1,2}$ As a fundamental element of public health and medical emergency planning and preparedness, law underlies aspects of public and private sector responses to disasters and pandemics. ${ }^{1}$ Among other things, law can help to establish more flexible response environments by authorizing actions that otherwise would not be permitted (eg, through declaring emergencies, waiving specific health-care laws and regulations, permitting care to be provided by foreign medical teams [FMTs], and so forth) and providing liability protections for specific health-care practitioners or entities engaged in good faith response actions. ${ }^{3,4}$

Conversely, law also can be used to hold hospitals and health-care workers (HCWs) that fail to appropriately plan for or respond to disasters accountable for resulting patient injuries and deaths. ${ }^{3,5-9}$ Focusing on the underlying legal duties of hospitals and critical care clinicians to appropriately plan for and deliver the best care possible to the greatest number of patients during disasters, we discuss legal suggestions developed by the American College of Chest Physicians (CHEST) Task Force on Mass Critical Care to facilitate and support planning and response efforts for mass casualty incidents involving critically ill or injured patients. The suggestions in this chapter are important for all of those involved in a disaster or pandemic with multiple critically ill patients, including front-line clinicians, hospitals, and public health or government officials. Although it is important for all providers to be familiar with all legal aspects of disaster and pandemic response, Table 1 provides an overview of the suggestions of most interest to each of the above groups. 


\section{Materials and Methods}

The Legal Panel adapted the CHEST Guidelines Oversight Committee's standard methodology, which was used to develop suggestions through a consensus development process focused on developing a representation of current disaster knowledge. This approach was carefully designed to identify and manage potential conflicts of interest (see the "Methodology" article by Ornelas et $\mathrm{al}^{10}$ in this consensus statement).

First, the Legal Panel developed 35 key questions based on expert knowledge of and experience with health-care and public health legal preparedness and response. The panel then conducted comprehensive literature searches to identify published literature to support suggestions that would be developed from the key questions. The literature searches included an evaluation of a range of materials (eg, peer-reviewed journal articles, government reports, media, legislation, case law). The authors conducted several reviews of the medical and legal literature covering dates ranging from 1995 to 2012 using MEDLINE/ PubMed, WestLaw, Lexis, or Scopus (search term examples include: crisis standards of care, disaster, legal, liability, immunity, indemnification, mass critical care, medical, public health emergency). Only English-language papers were included. This research process produced $>300$ publications. Two Legal Panel members independently evaluated each publication for relevance, initially resulting in approximately 140 publications for possible reference. Based on expert judgment, panel members supplemented these materials with additional publications that were not identified through the formal literature searches and also updated the searches with subsequently published materials throughout the consensus statement development and manuscript drafting processes.

Based on the literature reviews and expert opinions, the Legal Panel refined the original key questions and prepared suggested answers for them. Consensus among the Task Force was developed through the modified Delphi voting process.

\section{Results and Discussion}

1a. We suggest health agencies at all levels of government (ie, Local, Regional, State/ Province, and National) and relevant health-care system entities (eg, hospitals, long-term care facilities, and clinics) develop mass critical care (MCC) response plans in furtherance of a legal duty to prepare for mass critical care emergencies. These plans should be integrated into or with existing crisis standards of care, surge capacity, or other applicable health emergency plans and frameworks. The regional health authority (eg, in the US, state health departments) should facilitate and ensure the development of MCC plans at the sub-national and health-care facility levels to promote inter-jurisdictional consistency and collaboration within the state/province, across state/province lines, and with national partners

Health agencies and health-care system leaders have a legal duty to prepare for catastrophic emergencies. ${ }^{1,2,11-16}$ This imperative to plan has been reinforced and heightened by the impact of recent disasters on hospitals and health-care systems. Hurricanes Katrina (2005) and Sandy (2012) illustrate the severe patient harm, economic loss, and disruption to regional health systems due to the temporary closures of, or physical damages to, 
hospitals. ${ }^{5,14,17-19}$ The health-care-related impacts of these storms have also demonstrated that failing to appropriately respond to and adequately plan for disasters can expose HCWs and their supporting entities (eg, hospitals, clinics, nursing facilities) to serious liability claims. ${ }^{3,7,9,20,21}$

Collaborative planning at government and hospital levels is essential to effective MCC responses. Comprehensive, transparent planning efforts involving a multidisciplinary range of stakeholders and experts can formalize and legitimize response actions and promote consistency across facilities and jurisdictions. ${ }^{1}$ Collaboration can facilitate and promote plan acceptance; development of consistent triggers for activation and deactivation; and identification of clear and predictable lines of authority and decision-making, existing legal protections and gaps, and fair approaches for plan improvement and revision. ${ }^{1}$ Also integral to the planning process is identifying ethical principles to guide MCC decision-making (see the "Ethical Considerations" article by Daugherty Biddison et $\mathrm{al}^{22}$ in this consensus statement). ${ }^{23,24}$ To help confirm that MCC plans are just, as fair as possible, and accepted when implemented, comprehensive vetting by qualified experts and public engagement are needed (see the "Engagement and Education" article by Devereaux et $\mathrm{al}^{25}$ in this consensus statement). Training of all relevant responders must occur in advance of disasters. Such steps will help to facilitate equitable and systematic approaches to decision-making by officials, triage teams, HCWs, and other response actors during disasters and pandemics.

Planning and response efforts should occur with a focus on the entire response system, instead of in silos or ad hoc manners. A systems-based approach focusing on the interrelated components required for effective health-care responses will help to promote the goal of doing the greatest good for the largest number of patients and to prevent divergent responses within a jurisdiction or across neighboring jurisdictions. ${ }^{1}$ Regional health authorities (eg, in the United States, the state public health agency) typically lead such planning efforts because they are best positioned to: (1) establish the expectation that planning occurs at all levels within the region, (2) coordinate with planning efforts occurring in other regions and at national levels, (3) actively engage stakeholders, (4) use appropriate legal powers to authorize and provide liability protections for response actions, and (5) officially activate and deactivate response plans.

Failing to plan adequately, including by not involving appropriate stakeholders, collaborating throughout planning and response efforts, or educating stakeholders about plans, may contribute to findings of liability. ${ }^{26,27}$ It may also jeopardize patient safety and expose hospitals to major economic loss. ${ }^{28,29}$

\section{1b. We suggest MCC plans clarify approaches and processes for evacuating patients and for sheltering-in-place. This includes identifying the lines of authority for evacuation and shelter-in-place decision-making and the potential legal and ethical implications associated with such decisions}

Recognizing that extreme emergencies, such as hurricanes and floods, might overwhelm a health-care facility's ability to safely continue to care for patients, evacuation planning should be integrated into MCC emergency planning (see the "Evacuation of the ICU" article by King et al ${ }^{30}$ in this consensus statement). ${ }^{14,17,31,32}$ Hospitals are highly dependent on 
external infrastructure (eg, electricity, water, and communications) for basic functionality and patient safety, and backup systems have proven to be less than foolproof. For example, in the aftermath of Hurricane Katrina (2005), approximately 45 patients are estimated to have died at a single hospital after hospital generators failed and patients were not evacuated to safety early enough. ${ }^{6,33}$ Yet, evacuating medically complicated and fragile patients is complex and potentially dangerous to patients (see the "Evacuation of the ICU" article by King et $\mathrm{al}^{30}$ in this consensus statement). ${ }^{5}$ Contrasting the precautionary evacuations of hospitals in New York City before Hurricane Irene (2011) with the intraevent evacuations 1 year later during Hurricane Sandy (2012) demonstrates that a controlled, preplanned, collaborative evacuation may be safer than waiting to determine what to do in the midst of a disaster. ${ }^{5,34,35}$ However, precautionary evacuations may also pose risks to patients and are tremendously disruptive to patient care and facility operations at the evacuating and receiving facilities.

At a minimum, hospitals' emergency plans should ensure patient safety is at the foundation of evacuations and address: (1) how evacuation and sheltering-in-place decisions will be made and by whom, both within and external to a facility; (2) how to consider potentially conflicting decisions to evacuate when both public officials and private sector hospital leadership are empowered to make such calls within a jurisdiction; (3) if sheltering, how essential functions will be maintained; and (4) if evacuating, the process by which patients are triaged, how they are moved, where they might be sent, how continuity in access to patient health records can be ensured, and how to identify, locate, and accommodate highly vulnerable patients. ${ }^{19}$ Consensus suggestions regarding details of evacuation of critically ill patients can be found (see the "Evacuation of the ICU" article by King et al ${ }^{30}$ in this consensus statement). The failure of hospitals and jurisdictions to develop, implement, and coordinate adequate hospital evacuation plans can have serious legal, economic, and public health implications, including civil liability, sanctions, loss of accreditation, funding loss, access to care limitations, and stress on regional health-care systems. ${ }^{5,7,14,29}$

1c. We suggest MCC plans recognize the importance of responsible and accountable MCC decision-making among clinicians, government, and individual health-care entities by addressing how reviews of decisions made under the auspices of MCC plans will occur. Further, we suggest separate, efficient processes be developed to: (1) during the response, address fact-based appeals by ICU providers of decisions made during the response before resources are reallocated; and (2) following the response, review patient/ family member or ICU provider concerns about fidelity to the processes outlined in properly vetted and adopted MCC plans

Governmental entities, hospitals, triage officers or teams, and individual clinicians are responsible for adhering to applicable MCC plans. They also are accountable for the triage decisions they make and processes in which they are involved. ${ }^{23,36}$ Impromptu and independent departures by clinicians from formally adopted and vetted plans may have legal, ethical, and public health ramifications (see the "Ethical Considerations" article by Daugherty Biddison et $\mathrm{al}^{22}$ in this consensus statement). ${ }^{11}$ During MCC (and ideally before such emergencies through public engagement), ${ }^{1}$ it is critical that these practitioners effectively and transparently manage patient and family expectations upon arrival at the 
hospital. They should explain the circumstances and the measures being implemented to achieve the goal of saving as many lives as possible. Such communication should also occur during treatment. For example, if a patient requires mechanical ventilation, clinicians should clarify that ventilation is being used as a "trial" therapy; if the patient does not sufficiently improve, then the resource will be reallocated to one who may benefit according to preestablished, vetted triage protocols.

Even when expectations are appropriately managed, parties to triage decisions may still be aggrieved, since the available resources are inadequate to provide for all needs. Yet, time constraints on triage decisions play a pivotal role as to whether and how triage decisions should or even can be appealed or reviewed. Individual reviews of every decision in real time will paralyze the response system and potentially jeopardize patients' lives.

Separate, efficient, and transparent processes are needed for appeal and review of care decisions made during MCC responses. ${ }^{1}$ Collaborative MCC planning between government and private-sector health-care facility partners may reveal and lead to different approaches; in some cases, it may be possible to leverage or apply existing governmental policies and procedures to address MCC decision-making. These processes must strike a balance between ensuring fidelity to vetted triage plans and timely decision-making during a crisis. They should be developed as a component of the MCC planning process, incorporated into MCC plans and training, and clearly communicated to stakeholders. Comprehensive, inclusive approaches to developing MCC plans and the use of highly qualified, properly trained critical care physicians as triage officers (see the "Triage" article by Christian et al ${ }^{37}$ in this consensus statement) and responders should help to limit the occurrence of appeals and reviews outlined below. Any assessment of MCC decisions should consider the catastrophic emergency circumstances, acknowledging the inherent difficulties in carrying out triage and patient care even when MCC plans are followed in good faith. ${ }^{38}$

Clinical Appeal-One approach is an urgent, in-time, clinical appeal generated by an HCW when the clinician believes the clinical data used for the triage decision do not reflect the patient's condition. ${ }^{1,39}$ If the triage team reconsiders, the clinical course of treatment may be altered. ${ }^{1}$ The outcome of an appeal does not automatically imply a failure of performance or judgment of the triage team or treating team but should serve as an opportunity for ongoing education and plan evolution.

Process Appeal-Another approach is a process appeal, which is a retrospective review generated when a patient, family member, or clinician believes a decision was made unfairly or deviated substantially from guidelines without justification. Despite the absence of a process for individual, in-time appeals, retrospective review should be considered adequate and is all that can be reasonably expected in severe and protracted emergencies involving scarce resources and time-sensitive decision-making. ${ }^{1,40}$

If unfair or unjust decisions are found, processes should be in place for communicating them to invested individuals. ${ }^{40}$ Retrospective reviews should also assess whether clinicians unfairly allocated care by not following adopted processes between populations (eg, by ethnic or religious groups). ${ }^{3}$ Principles of equal protection do not dictate that all persons be 
treated identically; rather, treatment variations must be based on appropriate differences among individuals.

2. We suggest during declared emergencies: (1) government MCC plans be officially activated by the applicable governmental authority; and (2) individual health-care facility MCC plans be officially activated by clinical administrative leadership. We also suggest governments and individual health-care facilities develop approaches for the official deactivation of their MCC plans

Basic tenets of crisis standards of care include fairness and equitable process. ${ }^{1,2}$ These require that a change in patient care standards be part of an organized and collaborative response to a pandemic or disaster rather than individuals and/or entities acting in isolation. To facilitate and formalize changes in the provision of critical care and to discourage independent and ad hoc response actions, during declared emergencies and severe, protracted shortages of critical care resources, MCC plans should be officially activated. A formal declaration of an emergency, disaster, or public health emergency at the applicable governmental level validates the existence of the crisis. Activation of a hospital's MCC plan and communication of such activation to response partners (eg, through an existing healthcare coalition) help to reinforce and ensure that no individual—or hospital—is or should be acting independently. Also, in some cases, certain legal protections will not be triggered until requisite emergency declarations are made.

To maximize legal protections for providers and entities, if feasible both the emergency declaration and the plan activation should be in place before any changes in patient care are implemented. ${ }^{1}$ Jurisdictional and hospital emergency plans should include clearly identified indicators and triggers, procedures, and authorities for activating and deactivating emergency plans at any time. ${ }^{41}$

\section{3a. We suggest clinicians (both employees and volunteers) and health-care entities involved in the provision of critical care that follow properly vetted and officially-activated (1) governmental and (2) individual facility-level MCC plans in good faith should be protected legally from liability}

One of the premier threats to the public's health during disasters or pandemics is a lack of vetted and trained HCWs to care for patients. There are many reasons that clinicians may be in short supply in emergencies, including their reluctance to serve in the face of liability risks. Evidence shows that some clinicians will not participate fully, or at all, if they fear liability for their actions that result in unintentional harm to patients or even from foreseen harms that result from following appropriately vetted clinical guidelines for MCC. Absent protections, clinicians and hospitals face an array of potential civil liability threats (eg, allegations of medical malpractice, claims of constitutional violations, and so forth) as well as potential criminal liability.

Although some patients' rights advocates disagree, the need to protect HCWs from liability during emergency responses is a resounding theme. ${ }^{1,11,42-44}$ For example, in the United States, the federal Public Readiness and Emergency Preparedness (PREP) Act immunizes from tort liability HCWs engaged in the administration of covered medical 
countermeasures. ${ }^{45,46}$ State and local emergency laws provide extensive liability protections for clinicians acting under their scope of practice in declared emergencies. The Emergency Management Assistance Compact, ${ }^{47}$ agreed to by all US states, immunizes state/local agents working across state borders from liability. Federal- and state-based volunteer protection acts apply to unpaid, volunteer HCWs in emergencies. ${ }^{48}$ Some states' "Good Samaritan" provisions may even extend liability protections to clinicians responding to declared emergencies.

In the United States, these protections vary across jurisdictions. ${ }^{49-51}$ Lacking comprehensive federal protections despite multiple Congressional attempts, states are best positioned to set the scope and coverage of liability protections. Most laws in the United States tend to immunize HCWs, allowing them to avoid liability suits altogether. ${ }^{52,53}$ Some laws merely indemnify clinicians (meaning government will pay any successful claim against a covered worker). Despite these variations, collectively these laws present viable options for protecting clinicians from liability for negligent acts that occur during declared emergencies but not usually for wanton, willful, or criminal acts that harm patients. ${ }^{54}$ Competent clinicians or hospitals acting in good faith, which includes following formally adopted plans in accordance with applicable emergency declarations, should be reasonably protected from legal liability associated with their disaster-related actions. ${ }^{1,11,13,23,55,56}$

\section{3b. In sudden-onset emergencies (or in the early phases of other emergencies), it might not be feasible for governments to declare an emergency, or for governments and health- care facilities to immediately and officially activate their MCC plans. In such cases we suggest clinicians and health-care entities that provide MCC reasonably and in good faith be afforded liability protections (ie, absent gross negligence, willful misconduct, or criminal acts) through retroactive activation or application of declarations and plans or other appropriate legal routes}

Although some liability protections apply to HCWs any time they provide emergency services, the trigger for initiating many of these protections is the activation of emergency plans or, more likely, the formal declaration of emergencies. Relying on liability protections that arise only during plan activation or declared emergencies is problematic for several reasons. In the United States, for instance, federal, state, or local governments do not always quickly activate plans or declare formal emergencies even in the midst of pandemics or other public health crises. For example, although the severity of the emergency was much lower than originally expected, during the 2009 influenza A(H1N1) pandemic, only 12 states (and the federal government) declared states of emergency. Also, emergency declarations are often limited in duration. Of the states that declared emergencies in response to $\mathrm{A}(\mathrm{H} 1 \mathrm{~N} 1)$, most declarations lasted only 30 to 60 days, even though pandemic responses extended over months. Further, most emergency declarations have no retroactive effects. Coextensively, resulting liability protections only apply to clinicians' actions during the emergency declaration. One exception is power of the US Department of Health and Human Services to retroactively declare states of public health emergency. ${ }^{57}$

For these reasons, clinicians and hospitals acting in good faith—which implies acting consistently with vetted governmental and/or facility response plans-leading up to or 
immediately after emergency declarations or activation of MCC plans should be entitled to similar liability protections. Although not always possible, emergency declarations should be made retroactive to the beginning of crisis conditions, if appropriate.

4. We suggest governments develop approaches to formally and temporarily expand the available pool of qualified practitioners to address MCC staffing shortages and to ensure that all responding practitioners receive appropriate liability protections during a MCC response. Further, we suggest this could occur through implementing efficient processes for licensing, credentialing, and certifying in-country practitioners who are not normally authorized to practice in the impacted area to facilitate the emergency response; temporarily expanding professional scopes of practice for applicable types of health-care practitioners; and, if appropriate, accepting and using official, formally vetted foreign medical teams

When disasters or pandemics necessitate expansions in the number of responding HCWs and staffing cannot be sufficiently supplemented through resource-sharing agreements, ${ }^{58}$ implementation of official legal mechanisms that require minimum standards of HCW professional qualifications can facilitate the provision of a baseline and consistent level of patient care quality and provide administrative and tort liability protections. ${ }^{59-62}$ Options for supplementing MCC staffing must be carefully considered, in particular because highly specialized skills may be needed to provide care during mass casualty emergencies involving large numbers of critically ill and injured patients. ${ }^{63-66}$ Governments and hospitals should use approaches that are most appropriate for their response needs, including the following options for formally expanding pools of qualified responding clinicians.

Licensing, Credentialing, and Privileging Systems-Licensed HCWs who are not usually authorized to practice in the impacted hospital, health system, or region can be vetted and temporarily permitted to practice during the emergency. ${ }^{59-62}$ Preestablished mechanisms that facilitate recognition of out-of-state licenses and granting of temporary credentials and privileges can facilitate this. For example, in the United States, states have passed laws allowing recognition of out-of-state HCW licenses during emergencies, and the Emergency System for Advance Registration of Volunteer Health Professionals (ESARVHP) system allows states to verify the licenses of other states' HCWs that register with their state systems. ${ }^{67-69}$ Hospitals can also develop emergency systems to verify qualifications and extend temporary credentials and privileges during an emergency or its aftermath; in the United States, an accreditation body requires hospitals to have such systems. ${ }^{70}$ Following Hurricane Sandy (2012), for example, many New York City hospitals remained closed for months. ${ }^{5} \mathrm{HCW}$ s were granted temporary privileges to work at neighboring facilities that remained open so that services could continue to be provided to the population experiencing a sudden, severe, and ongoing shortage of facilities (Gary Kalkut, MD, MPH, to T.P., personal communication, December 2012).

Scope of Practice Expansions-Through this approach, certain categories of licensed or certified health professionals (eg, nurses, physician assistants, dentists) are temporarily authorized during a response to provide services outside of their normal scopes of practice. ${ }^{2}$ For example, during the $2009 \mathrm{~A}(\mathrm{H} 1 \mathrm{~N} 1)$ pandemic, some US states addressed increased 
demand for pandemic vaccines by temporarily permitting pharmacists, dentists, emergency medical services professionals, or other clinicians to administer vaccine through various legal approaches (eg, executive order, emergency regulation.). ${ }^{71,72}$ Although each state independently regulates the practices of its licensed health professionals, significant differences in approaches to scope of practice expansions can contribute to response complexities and confusion when in-state and out-of-state HCWs are involved.

Foreign Medical Teams-When HCW staffing cannot be met through domestic personnel during a disaster, supplementing staffing with FMTs may be needed. Ideally, FMTs should be used only if they have been prequalified and preregistered in advance and are coordinated through an appropriate international body (eg, United Nations, World Health Organization, and so forth) that sets minimum professional and ethical standards for inclusion in an official FMT registry. ${ }^{73-76}$ Receiving nations should have plans in place to formally and rapidly invite and accept (eg, through recognizing these vetted foreign responders' licensing and credentialing and deeming them federal agents during the response), integrate into domestic operations, legally protect, and demobilize such teams. ${ }^{77}$ Team members acting in good faith and under the auspices of their official team should receive appropriate liability protections similar to those of domestic clinicians responding to the disaster or pandemic.

\section{Areas for Research}

Significant progress in health-care and public health planning for disasters and pandemics, including strengthened legal preparedness for such emergencies, has occurred over the last decade and since the publication of the initial statement from CHEST in 2008. However, several areas of legal preparedness warrant future exploration and research as comprehensive efforts to strengthen MCC preparedness evolve. These issues may raise different types of challenges, depending on the scale and severity of the disaster or pandemic and whether the event occurs in a resource-poor or resource-rich environment.

For example, formal processes for vetting, coordinating, and integrating FMTs, and for determining appropriate standards of practice, are still under development. Although a potentially critical response asset, the use of FMTs raises a host of legal and regulatory issues for both responding and receiving countries. Challenges range from addressing foreign $\mathrm{HCW}$ liability to importing, exporting, and using foreign medical materiel (eg, drugs, vaccines, and devices).

Additionally, although the primary focus of the healthcare response to a disaster or pandemic should be on optimizing patient care, conducting intra-event research and surveillance during disasters is critical for informing a response's interventions, as well as those for future responses, and involves legal and regulatory aspects. ${ }^{78}$ Response challenges and national variations, including those related to obtaining informed consent, receiving institutional review board approval efficiently (eg, through central institutional review boards), and developing appropriate and adaptable standing protocols for disaster research, remain. ${ }^{79}$ Disaster-related research challenges also may be associated with determinations 
about the feasibility of continuing important clinical research that commenced before the emergency began but that might not be directly related to the emergency itself.

National, regional, and/or provincial/state health authorities may need to assess whether existing disaster response laws and protections are sufficient to meet their disaster and pandemic response needs and concerns and consider enacting legislative or regulatory changes to strengthen their legal preparedness if critical gaps are identified. Additional MCC legal and regulatory challenges in need of further exploration include, but are not limited to, expectations for maintaining patient identification and health records (eg, through preestablished processes for alternate record keeping); plans for making critical patient health information readily available to appropriate responders through electronic tools (eg, health information exchanges), while also protecting the privacy and security of health record information, particularly when patients are evacuated ${ }^{80,81}$; and mechanisms for authorizing the emergency use of medical countermeasures, including products that might not yet be approved for use.

\section{Conclusions}

Legal and policy preparedness for disasters and pandemics, including those necessitating shifts to crisis standards of care, has evolved dramatically since Hurricane Katrina, and recent disasters have demonstrated other significant gaps in health-care preparation on multiple levels. In the United States, for example, many localities have examined their medical and public health response capabilities for disasters. Most have disaster plans in place and recognize the duty and imperative for coordinating with other local, regional, and federal partners. Various legal protections for specific responders have been enacted at the local, state, and federal levels. Health disaster response planning and coordination have also evolved at the international level.

Acceptance for the health-care community's obligation to appropriately plan for and respond to disasters and pandemics is widespread. Indeed, fear of liability in the absence of adequate plans is a likely motivating factor for many entities within health care and government to assess and update their response capabilities. Whether all plans are capable of implementation in the event of actual disaster remains unproven. Some plans are less comprehensive than others, and there are ultimately limits to the ability to predict and prepare for disasters. No single approach can provide a shield from all claims of liability. However, comprehensive and collaborative MCC planning efforts are essential to effective responses to mass casualty incidents involving critically ill or injured patients. They can help facilitate transparent, consistent, and sound decision-making among health-care entities and practitioners during responses and may provide important liability protections to healthcare entities and practitioners for good faith actions during emergencies.

\section{Acknowledgments}

FUNDING/SUPPORT: This publication was supported by the Cooperative Agreement Number 1U90TP00591-01 from the Centers of Disease Control and Prevention, and through a research sub award agreement through the Department of Health and Human Services [Grant 1 - HFPEP070013-01-00] from the Office of Preparedness of Emergency Operations. In addition, this publication was supported by a grant from the University of CaliforniaDavis. 


\section{ABBREVIATIONS}

$\begin{array}{ll}\text { FMT } & \text { foreign medical team } \\ \text { HCW } & \text { health-care worker } \\ \text { MCC } & \text { mass critical care }\end{array}$

\section{References}

1. IOM (Institute of Medicine). Crisis Standards of Care: A Systems Framework for Catastrophic Disaster Response. Washington, DC: The National Academies Press; 2012.

2. IOM (Institute of Medicine). Guidance for Establishing Crisis Standards of Care for Use in Disaster Situations: A Letter Report. Washington, DC: The National Academies Press; 2009.

3. Hodge JG Jr, Garcia AM, Anderson ED, Kaufman T. Emergency legal preparedness for hospitals and health care personnel. Disaster Med Public Health Prep. 2009; 3(suppl 2):S37-S44. [PubMed: 19491586]

4. Anderson ED, Hodge JG Jr. Emergency legal preparedness among select US local governments. Disaster Med Public Health Prep. 2009; 3(suppl 2):S176-S184. [PubMed: 19797962]

5. Powell T, Hanfling D, Gostin LO. Emergency preparedness and public health: the lessons of Hurricane Sandy. JAMA. 2012; 308(24):2569-2570. [PubMed: 23281545]

6. Fink, S. [Accessed August 7, 2014] Strained by Katrina, a hospital faced deadly choices. New York Times Magazine. Aug 25. 2009 http://www.nytimes.com/2009/08/30/magazine/30doctors.html

7. Hodge JG Jr, Brown EF. Assessing liability for health care entities that insufficiently prepare for catastrophic emergencies. JAMA. 2011; 306(3):308-309. [PubMed: 21771993]

8. Preston v. Tenet Healthsystem Memorial Medical Center Inc, No. 05-11709-B-15 (LA Civ Dist Ct settled March 23, 2011).

9. Fink, S. Five Days at Memorial: Life and Death in a Storm-Ravaged Hospital. New York, NY: Crown Publishers; 2013.

10. Ornelas J, Dichter JR, Devereaux AV, Kissoon N, Livinski A, Christian MD. on behalf of the Task Force for Mass Critical Care. Methodology: care of the critically ill and injured during pandemics and disasters: CHEST consensus statement. Chest. 2014; 146(4_suppl):35S-41S. [PubMed: 25144246]

11. Devereaux AV, Dichter JR, Christian MD, et al. Task Force for Mass Critical Care. Definitive care for the critically ill during a disaster: a framework for allocation of scarce resources in mass critical care: from a Task Force for Mass Critical Care summit meeting, January 26-27, 2007, Chicago, IL. Chest. 2008; 133(suppl 5):51S-66S. [PubMed: 18460506]

12. US Department of Health and Human Services, Agency for Healthcare Research and Quality (AHRQ). Altered Standards of Care in Mass Casualty Events. Rockville, MD: Agency for Healthcare Research and Quality; 2005. AHRQ Publication No. 05-0043

13. Courtney B, Hodge JG Jr. Task Force for Pediatric Emergency Mass Critical Care. Legal considerations during pediatric emergency mass critical care events. Pediatr Crit Care Med. 2011; 12(suppl 6):S152-S156. [PubMed: 22067924]

14. Hodge JG, Collmer V. A legal duty to evacuate patients from healthcare facilities in emergencies. The Health Lawyer. 2013; 25(3):20-23.

15. Pahlman I, Tohmo H, Gylling H. Pandemic influenza: human rights, ethics and duty to treat. Acta Anaesthesiol Scand. 2010; 54(1):9-15. [PubMed: 19919583]

16. US Department of Health and Human Services, Centers for Medicare \& Medicaid Services. Proposed Rule: 37. Emergency preparedness requirements for Medicare and Medicaid participating providers and suppliers (CMS-3178-P) (Section 610 Review).

17. Franco C, Toner E, Waldhorn R, Maldin B, O’Toole T, Inglesby TV. Systemic collapse: Medical care in the aftermath of Hurricane Katrina. Biosecur Bioterror. 2006; 4(2):135-146. [PubMed: 16792481] 
18. Redlener I, Reilly MJ. Lessons from Sandy_preparing health systems for future disasters. N Engl J Med. 2012; 367(24):2269-2271. [PubMed: 23171063]

19. Powell, M.; Fink, S. [Accessed August 7, 2014] Nursing home is faulted over care after storm. New York Times. Nov 10. 2012 http://www.nytimes.com/2012/11/10/nyregion/queens-nursinghome-is-faulted-over-care-after-storm.html

20. Fink, S. New York Times. Jan 1. 2010 The New Katrina flood: hospital liability.

21. In the Matter of Maison Deville Nursing Home, 797 So.2d 728,730 (La. App. 1 Cir. June 22, 2001).

22. Daugherty Biddison L, Berkowitz KA, Courtney B, et al. on behalf of the Task Force for Mass Critical Care. Ethical considerations: care of the critically ill and injured during pandemics and disasters: CHEST consensus statement. Chest. 2014; 146(4_suppl):e145S-e155S. [PubMed: 25144262]

23. Levin D, Cadigan RO, Biddinger PD, Condon S, Koh HK. Joint Massachusetts Department of Public Health-Harvard Altered Standards of Care Working Group. Altered standards of care during an influenza pandemic: identifying ethical, legal, and practical principles to guide decision making. Disaster Med Public Health Prep. 2009; 3(suppl 2):S132-S140. [PubMed: 19755912]

24. Hodge JG Jr, Hanfling D, Powell TP. Practical, ethical, and legal challenges underlying crisis standards of care. J Law Med Ethics. 2013; 41(suppl 1):50-55. [PubMed: 23590741]

25. Devereaux AV, Tosh PK, Hick JL, et al. on behalf of the Task Force for Mass Critical Care. Engagement and education: care of the critically ill and injured during pandemics and disasters: CHEST consensus statement. Chest. 2014; 146(4_suppl):e118S-e133S. [PubMed: 25144161]

26. Weiser, B. [Accessed August 7, 2014] Suit may go on in disaster plan for the disabled. New York Times. Nov 8. 2012 http://www.nytimes.com/2012/11/09/nyregion/suit-proceeds-over-citysdisaster-planning-for-disabled-people.html

27. Network for Public Health Law. Legal Brief: Communities Actively Living Independent and Free (CALIF) v. City of Los Angeles. Feb 11. 2011

28. Hartocollis, A. New York Times. Jan 24. 2013 Health chief defends decision not to evacuate hospitals.

29. Fink, S. [Accessed August 7, 2014] Class-action suit filed after Katrina hospital deaths settled for \$25 million. ProPublica. Jul 21. 2011 http://www.propublica.org/article/class-action-suit-filedafter-katrina-hospital-deaths-settled-for-25-millio

30. King MA, Niven AS, Beninati W, et al. on behalf of the Task Force for Mass Critical Care. Evacuation of the ICU: care of the critically ill and injured during pandemics and disasters: CHEST consensus statement. Chest. 2014; 146(4_suppl):e44S-e60S. [PubMed: 25144509]

31. Editorial. [Accessed August 7, 2014] Hospital evacuations for future storms. New York Times. Nov 6. 2012 http://www.nytimes.com/2012/11/07/opinion/hospital-evacuations-for-futurestorms.html

32. Sulzberger, AG.; Stelter, B. [Accessed August 7, 2014] A rush to protect patients, then bloody chaos. New York Times. May 23. 2011 https://www.nytimes.com/2011/05/24/us/24tornado.html? _r=1\&pagewanted=all

33. Gray, BH.; Hebert, K. Hospitals in Katrina: Challenges Facing Custodial Institutions in a Disaster. The Urban Institute; 2006. http://www.urban.org/UploadedPDF/411348_katrinahospitals.pdf [Accessed August 7, 2014]

34. Fink, S. [Accessed August 7, 2014] In hurricane's wake, decisions not to evacuate hospitals raise questions. ProPublica. Nov 1. 2012 http://www.propublica.org/article/in-hurricanes-wakedecisions-not-to-evacuate-hospitals-raise-questions

35. Kolker, R. New York Magazine. Nov 3. 2012 A hospital flatlined: inside the NYU Langone Medical Center evacuation.

36. Brown LM, Hyer K, Polivka-West L. A comparative study of laws, rules, codes and other influences on nursing homes' disaster preparedness in the Gulf Coast states. Behav Sci Law. 2007; 25(5):655-675. [PubMed: 17899530]

37. Christian MD, Sprung CL, King MA, et al. on behalf of the Task Force for Mass Critical Care. Triage: care of the critically ill and injured during pandemics and disasters: CHEST consensus statement. Chest. 2014; 146(4_suppl):e61S-e74S. [PubMed: 25144591] 
38. Hodge JG Jr, Courtney B. Assessing the legal standard of care in public health emergencies. JAMA. 2010; 303(4):361-362. [PubMed: 20103761]

39. Hick JL, Rubinson L, O'Laughlin DT, Farmer JC. Clinical review: allocating ventilators during large-scale disasters-problems, planning, and process. Crit Care. 2007; 11(3):217-225. [PubMed: 17601354]

40. Debruin, DA.; Marshall, MF.; Parilla, E., et al. Implementing Ethical Frameworks for Rationing Scarce Health Resources in Minnesota During Severe Influenza Pandemic. Minneapolis, MN: Minnesota Department of Health; 2010. http://www.health.state.mn.us/divs/idepc/ethics/ implement.pdf

41. IOM (Institute of Medicine). Crisis Standards of Care: A Toolkit for Indicators and Triggers. Washington, DC: The National Academies Press; 2013.

42. Hodge JG, Anderson ED. Principles and practice of legal triage during public health emergencies. NYU Ann Surv Am L. 2008; 64(2):249-291.

43. Gostin LO, Hanfling D, Hodge JG Jr, Courtney B, Hick JL, Peterson CA. Standard of care-in sickness and in health and in emergencies. N Engl J Med. 2010; 363(14):1378-1379. [PubMed: 20879893]

44. Mareiniss DP, Levy F, Regan L. ICU triage: the potential legal liability of withdrawing ICU care during a catastrophic event. Am J Disaster Med. 2011; 6(6):329-338. [PubMed: 22338314]

45. 42 U.S.C. $\$ 247 d-6 d(2006)$.

46. Courtney B, Sherman S, Penn M. Federal legal preparedness tools for facilitating medical countermeasure use during public health emergencies. J Law Med Ethics. 2013; 41(suppl 1):22_ 27. [PubMed: 23590735]

47. Emergency Management Assistance Compact. Pub. L. No. 104-321; 110 Stat. 3877(1996).

48. Hodge JG Jr, Gable LA, Cálves SH. Volunteer health professionals and emergencies: assessing and transforming the legal environment. Biosecur Bioterror. 2005; 3(3):216-223. [PubMed: 16181044]

49. Hoffman S. Responders' responsibility: liability and immunity in public health emergencies. Georgetown Law J. 2008; 96(6):1913-1970.

50. Hoffman S, Goodman RA, Stier DD. Law, liability, and public health emergencies. Disaster Med Public Health Prep. 2009; 3(2):117-125. [PubMed: 19092672]

51. Rosenbaum S, Harty MB, Sheer J. State laws extending comprehensive legal liability protections for professional health-care volunteers during public health emergencies. Public Health Rep. 2008; 123(2):238-241. [PubMed: 18457079]

52. La Rev Stat Ann $§ 29: 735.3$ (2008).

53. Va Code Ann §8.01-225.01-02 (2008).

54. La Rev Stat Ann $\$ 37: 1731.1$ (2008).

55. AMA (American Medical Association). House of Delegates Resolution 206: Uniform Emergency Volunteer Health Practitioners Act. Chicago, IL: AMA; 2008.

56. Koch VG, Roxland BE. Unique proposals for limiting legal liability and encouraging adherence to ventilator allocation guidelines in an influenza pandemic. DePaul J Health Care Law. 2013; 14(3): 467-501.

57. Public Health Security and Bioterrorism Preparedness and Response Act of 2002. Pub. L. No. 107-188; 116 Stat 594 (2002).

58. Kerlin, A. Reuters. Apr 19. 2013 Preparedness law allowed Boston to quickly pool medical resources.

59. Jangi S. Facing uncertainty_dispatch from Beth Israel Medical Center, Manhattan. N Engl J Med. 2012; 367(24):2267-2269. [PubMed: 23151280]

60. The Joint Commission. Surge Hospitals: Providing Safe Care in Emergencies. Oakbrook Terrace, IL: Joint Commission; 2005.

61. Baumann AO, Blythe JM, Underwood JM. Surge capacity and casualization: Human resource issues in the post-SARS health system. Can J Public Health. 2006; 97(3):230-232. [PubMed: 16827414]

62. Kellermann AL. Crisis in the emergency department. N Engl J Med. 2006; 355(13):1300-1303. [PubMed: 17005946] 
63. Boyajian-O’Neill LA, Gronewold LM, Glaros AG, Elmore AM. Physician licensure during disasters: a national survey of state medical boards. JAMA. 2008; 299(2):169-171. [PubMed: 18182598]

64. Hodge JG, Calves SH, Gable L, et al. Risk management in the wake of hurricanes and other disasters: hospital civil liability arising from the use of volunteer health professionals during emergencies. Mich St J Med \& Law. 2006; 10(1):57-86.

65. Weeks EA. Lessons from Katrina: response, recovery and the public health infrastructure. DePaul J Health Care Law. 2007; 10(2):251-290.

66. Courtney B. Five legal preparedness challenges for responding to future public health emergencies. J Law Med Ethics. 2011; 39(suppl 1):60-64. [PubMed: 21309899]

67. U.S. Department of Health and Human Services (HHS). Emergency System for Advance Registration of Volunteer Health Professionals (ESAR-VHP): Legal and Regulatory Issues. Washington, DC: HHS; 2009.

68. Ransom MM, Goodman RA, Moulton AD. Addressing gaps in health care sector legal preparedness for public health emergencies. Disaster Med Public Health Prep. 2008; 2(1):50-56. [PubMed: 18388658]

69. Hodge JG, Gable LA, Calves SH. The legal framework for meeting surge capacity through the use of volunteer health professionals during public health emergencies and other disasters. J Contemp Health Law Policy. 2005; 22(1):5-71. [PubMed: 16680989]

70. The Joint Commission. Disaster Privileging Standard. Comprehensive Accreditation Manual for Hospitals. Medical Staff Section MS.5.14.4.1

71. Courtney B, Morhard R, Bouri N, Cicero A. Expanding practitioner scopes of practice during public health emergencies: experiences from the $2009 \mathrm{H} 1 \mathrm{~N} 1$ pandemic vaccination efforts. Biosecur Bioterror. 2010; 8(3):223-231. [PubMed: 20825333]

72. [Accessed August 7, 2014] N.Y. Executive Order No. 29. Declaring a Disaster Emergency in the State of New York. Oct 28. 2009 http://www.governor.ny.gov/archive/paterson/executiveorders/ eo_29.html

73. WHO (World Health Organization). [Accessed August 7, 2014] FMT Concept Paper. Mar. 2011 http://www.who.int/hac/global_health_cluster/about/ ghc_annex9_field_medical_team_concept_note_18march2011.pdf

74. INSARAG (International Search and Rescue Advisory Group). [Accessed August 7, 2014] INSARAG Guidelines and Methodology. 2012. http://www.insarag.org

75. Redmond AD, O'Dempsey TJ, Taithe B. Disasters and a register for foreign medical teams. Lancet. 2011; 377(9771):1054-1055. [PubMed: 21440794]

76. Fisher D. Regulating the helping hand: improving legal preparedness for cross-border disaster medicine. Prehosp Disaster Med. 2010; 25(3):208-212. [PubMed: 20586011]

77. IFRC (International Federation of Red Cross and Red Crescent Societies), OCHA (United Nations Office for the Coordination of Humanitarian Affairs), and Inter-Parliamentary Union. [Accessed August 7, 2014] Model Act for the Facilitation and Regulation of International Disaster Relief and Initial Recovery Assistance (with commentary). http://www.ifrc.org/docs/IDRL/MODEL\%20ACT \%20ENGLISH.pdf. Published 2013

78. Lurie N, Manolio T, Patterson AP, Collins F, Frieden T. Research as a part of public health emergency response. N Engl J Med. 2013; 368(13):1251-1255. [PubMed: 23534565]

79. USCIITG (United States Critical Illness and Injury Trials Group). [Accessed August 7, 2014] USCIITG-PREP (Program for Emergency Preparedness). http://www.usciitg.org/?page_id=45

80. US Department of Health and Human Services, Agency for Healthcare Research and Quality (AHRQ). Regional Health e-Decisions: A Guide to Connect Health Information Exchange in Primary Care. Rockville, MD: Agency for Healthcare Research and Quality; 2013. AHRQ Publication No. 13-0018-EF

81. US Department of Health and Human Services, Office of the National Coordinator for Health Information Technology (ONC). Southeast Regional HIT-HIE Collaboration (SERCH): Final Report; ONC State Health Policy Consortium Project: Health Information Exchange in Disaster Preparedness and Response. Washington, DC: US Department of Health and Human Services; 2012. 


\section{Summary of Suggestions}

1a We suggest health agencies at all levels of government (ie, Local, Regional, State/Province, and National) and relevant health-care system entities (eg, hospitals, long-term care facilities, and clinics) develop mass critical care (MCC) response plans in furtherance of a legal duty to prepare for mass critical care emergencies. These plans should be integrated into or with existing crisis standards of care, surge capacity, or other applicable health emergency plans and frameworks. The regional health authority (eg, in the US, state health departments) should facilitate and ensure the development of mass critical care plans at the sub-national and health-care facility levels to promote inter-jurisdictional consistency and collaboration within the state/ province, across state/province lines, and with national partners.

1b We suggest MCC plans clarify approaches and processes for evacuating patients and for shelteringin-place. This includes identifying the lines of authority for evacuation and shelter-in-place decision-making and the potential legal and ethical implications associated with such decisions.

1c We suggest MCC plans recognize the importance of responsible and accountable MCC decision-making among clinicians, government, and individual health-care entities by addressing how reviews of decisions made under the auspices of MCC plans will occur. Further, we suggest separate, efficient processes be developed to: (1) during the response, address factbased appeals by ICU providers of decisions made during the response before resources are reallocated; and (2) following the response, review patient/ family member or ICU provider concerns about fidelity to the processes outlined in properly-vetted and adopted MCC plans.

2 We suggest during declared emergencies: (1) government MCC plans be officially activated by the applicable governmental authority; and (2) individual health-care facility MCC plans be officially activated by clinical administrative leadership. We also suggest governments and individual health-care facilities develop approaches for the official deactivation of their MCC plans.

3a We suggest clinicians (both employees and volunteers) and health-care entities involved in the provision of critical care that follow properly-vetted and officially-activated (1) governmental and (2) individual facility-level MCC plans in good faith should be protected legally from liability.

3b In sudden-onset emergencies (or in the early phases of other emergencies), it might not be feasible for governments to declare an emergency, or for governments and health-care facilities to immediately and officially activate their MCC plans. In such cases we suggest clinicians and health-care entities that provide MCC reasonably and in good faith be afforded liability protections (ie, absent gross negligence, willful misconduct, or criminal acts) 
through retroactive activation or application of declarations and plans or other appropriate legal routes.

4 We suggest governments develop approaches to formally and temporarily expand the available pool of qualified practitioners to address MCC staffing shortages and to ensure that all responding practitioners receive appropriate liability protections during a MCC response. Further, we suggest this could occur through implementing efficient processes for licensing, credentialing, and certifying in-country practitioners who are not normally authorized to practice in the impacted area to facilitate the emergency response; temporarily expanding professional scopes of practice for applicable types of health-care practitioners; and, if appropriate, accepting and using of official, formally vetted foreign medical teams. 
TABLE 1

Primary Target Audiences for Suggestions

\begin{tabular}{l|c|c|c}
\hline \multirow{2}{*}{ Suggestion Number } & \multicolumn{3}{|c}{ Primary Target Audience } \\
\cline { 2 - 4 } & Clinicians & Hospital Administrators & Public Health/Government \\
\hline $1 \mathrm{a}$ & & $\checkmark$ & $\checkmark$ \\
\hline $\mathrm{b}$ & & $\checkmark$ & $\checkmark$ \\
\hline $1 \mathrm{c}$ & $\checkmark$ & $\checkmark$ & $\checkmark$ \\
\hline 2 & & $\checkmark$ & $\checkmark$ \\
\hline $3 \mathrm{a}$ & $\checkmark$ & $\checkmark$ & $\checkmark$ \\
\hline $3 \mathrm{~b}$ & $\checkmark$ & $\checkmark$ & $\checkmark$ \\
\hline 4 & $\checkmark$ & & $\checkmark$ \\
\hline
\end{tabular}

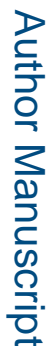

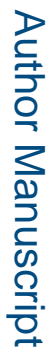

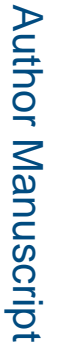

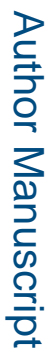

